\title{
Recent Trend in Variability of Chum Salmon Stock and its Potential Mechanism in Hokkaido, Japan
}

\author{
Hirokazu Urabe ${ }^{1}$, Hayato Saneyoshi ${ }^{1}$, and Makoto Hatakeyama ${ }^{2}$

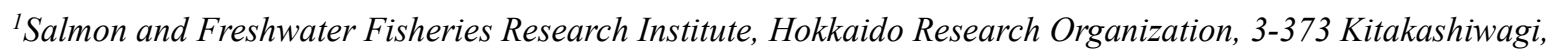 \\ Eniwa, Hokkaido, Japan \\ ${ }^{2}$ Central Fisheries Research Institute, Hokkaido Research Organization, 238 Yoichi, Hokkaido, Japan
}

Keywords: chum salmon, ocean condition, sea surface temperature, age at maturity, growth rate

Chum salmon stock in Hokkaido has been declining since its peak in 2004. In 2017, its stock level reached the lowest level over the past 30 years. In addition, we observed that the stock levels were lower than what we predicted using the sibling regression method. In such a situation, both improving hatchery programs and enhancing the accuracy of the pre-season forecast are essential to managing the chum salmon stock in Hokkaido. We explored factors affecting the variability in-stock level and precision of the pre-season forecast.

We calculated the number of chum salmon caught in Hokkaido as the sum of the number of fish caught by the coastal fishery and the number of fish caught in rivers over the period 1986-2020. The number of salmon caught by the coastal fishery is based on data published by the Hokkaido Prefectural Government, and the number of salmon caught in rivers is based on data published by the Hokkaido salmon enhancement association, a public interest incorporated foundation. The return rates of salmon were calculated for 1983-2015 brood years, which were caught during 1986-2020 as three- to five-year-old fish in Hokkaido, using the number of fish released and the number of fish caught described above. The return rates were calculated only for the Pacific coast area, which has had a significant impact on the stock variations of chum salmon in Hokkaido. In order to clarify the relationship between the return rates and coastal sea surface temperatures (SSTs), we conducted regression analyses between monthly average sea surface temperatures from April to June, when chum salmon juveniles enter the ocean and grow in coastal areas (Irie 1990; Seki 2005), at the Pacific coastal areas and return rate of salmon at the Pacific coast. For the calculation of the monthly average sea surface temperatures, we used SSTs for ten areas along the Pacific coast published by the Japan Meteorological Agency (Available at https://www.data.jma.go.jp/gmd/kaiyou/data/db/SP/dbindex_SP.html).

Our analyses revealed that the return rate of chum salmon is positively correlated with coastal sea surface temperature (SST) at ocean entry timing. This suggests that the SST during the ocean entry timing of chum salmon juveniles would be a major driver in controlling the year-class abundance and that the decline of the stock level would be caused by the "cold-spring" SST phase around Hokkaido. In 2016, the ocean regime around Hokkaido changed to a warmer condition; however, the 4-year-old fish abundance of the 2015 year-class has not recovered, and a deviation between pre-season forecast and actual abundance has increased, as well.

We found that the deviations between pre-season forecast and actual abundance were mainly caused by overestimating the abundance of 4-year-old fish. We analyzed the relationships between age at maturity of year classes and the ratio of 4-year-old fish to 3-year-old fish abundance, known as sibling relationship, to identify the factors affecting these overestimations. Our analyses revealed that the age at maturity had decreased in most areas, and it would affect the sibling relationships.

These results suggest that the decline of chum salmon stock levels in Hokkaido would have been mainly caused by cold ocean conditions during spring. In addition, the analysis for the 2015 year-class, which matched favorable ocean conditions in the coastal area, suggests that the survival rate in the Okhotsk Sea and/or farther area might be recently decreasing. The decline of the age at maturity, which affects the sibling relationship, suggests that the survival rate of fish with a slower growth rate might be decreasing.

\section{REFERENCES}

Irie, T. 1990. Ecological studies on the migration of juvenile chum salmon, Oncorhynchus keta, during early ocean life. Bull. Seikai Natl. Fish. Res. Inst. 68: 1-142. (In Japanese with English summary)

Seki, J. 2005. Study of characteristic of feeding habitat of juvenile chum salmon and their food environment in the Pacific coastal waters, central part of Hokkaido. Bull. Nat. Salmon Resources Center 7: 1-104. (In Japanese with English abstract) 